\title{
Seasonal resource use and niche breadth in an assemblage of coexisting grazers in a fenced Park
}

\author{
Shem M. Mwasi ${ }^{1 *}$, Sipke E. Van Wieren ${ }^{2}$, Ignas M. A. Heitkönig ${ }^{2}$, Herbert H. T. Prins ${ }^{2}$ \\ ${ }^{1}$ School for Field Studies, Center for Wildlife Management Studies, Nairobi, Kenya; ${ }^{*}$ Corresponding Author: smwasi@,fieldstudies.org \\ ${ }^{2}$ Resource Ecology Group, Wageningen University, Wageningen, The Netherlands
}

Received 17 July 2013; revised 25 August 2013; accepted 2 September 2013

Copyright (C) 2013 Shem M. Mwasi et al. This is an open access article distributed under the Creative Commons Attribution License, which permits unrestricted use, distribution, and reproduction in any medium, provided the original work is properly cited.

\section{ABSTRACT}

Many small Parks in Kenya are being fenced to control human-wildlife conflict. Some of these Parks have a diversity of large herbivores which might increase in density in the wake of fencing and subsequent compression of their home ranges due to closure of their migratory routes. It is important to understand the consequences of such an increase on the structuring of insularised herbivore assemblages in such Parks. We studied seasonal resource segregation and niche breadth variation as mechanisms of coexistence in a high density grazer assemblage in Lake Nakuru National Park which is small and completely fenced. Diet composition and habitat use were considered as variables of resource use. We predicted that overlap in resource use and niche breadth would be the smallest among grazers with similar body weights in the dry season which is the most resource limiting for grazers in East Africa. Our results were contrary to the predictions because of lack of seasonal differentiation in the overlap of diet composition and habitat use, and in niche breadth. Overlaps in resource use were consistently high during both the wet and dry seasons, and niche breadth contraction during the dry season was not possible probably because of lack of species-specific niches during the dry season. Our results suggest that there might be competitive interactions in this grazer assemblage which is an important parameter to consider in the management of the Park.

Keywords: Niche Breadth; Diet Composition; Coexistence; Habitat Use; Overlap; Season; Grazer; Competitive Interactions

\section{INTRODUCTION}

The mechanisms by which coexistence of apparently many similar grazing ungulates is made possible have been a subject of study for some time [1-4]. A number of mechanisms have been identified by which resource segregation between large grazers become possible during coexistence. Among these mechanisms are physiological adaptations [5], interspecific differences in incisor arc width [6] and differences in body weight [4]. In case one or combinations of these mechanisms are not adhered to, then competitive interactions among grazers are expected to occur. Although competitive interactions in the field are hard to detect, a body of evidence $[4,7,8]$ proves that these interactions play a role in the structuring and functioning of many large grazer assemblages.

Forage quantity of large grazers in East Africa varies with seasons, which are primarily defined by the amount of rainfall received in an area during a particular period in a year. Intra-annual rainfall in these areas is correlated with primary production $[9,10]$. During a dry season with little or no rainfall, above ground green standing crop biomass might be relatively low, while a wet season is characterised by a high green standing crop biomass. An increase in green standing crop biomass is generally associated with improved quality of forage $[11,12]$. Therefore, both from the perspective of food availability and that of food quality, the dry season will generally be the most limiting in East Africa. It is expected that, in the dry season, resource segregation among coexisting grazers becomes more pronounced as they specialise in resource use to avoid interacting competitively with each other $[8,13,14]$. Their niche breadth in resource use also becomes smaller [15], while the reverse is expected during the non-limiting season when resources are abundant. It is also expected that during the non-limiting season, grazers in similar body weight classes will overlap more in resource use and have wider niche breadth in resource 
use. These predictions have indeed been demonstrated in a number of grazer assemblages [16-19].

Studies in overlap of resource use and variation in niche breadth in dense assemblages of grazers in small fenced National Parks where there is no dry or wet season grazer migration have not been reported in literature. With this background we assessed overlap in seasonal diet composition and habitat use as major variables of overlap in resource use, and the implications of niche breadth in diet composition and habitat use on a high density assemblage of six coexisting large grazers of different body weights in Lake Nakuru National Park, Kenya which is a small Park $\left(188 \mathrm{~km}^{2}\right)$ that has been completely fenced since 1977 . The study hypothesised that, overlap in resource use between species in similar body weight classes, would be lowest in the dry season, and niche breadth in resource use would be smallest during the dry season.

\section{MATERIALS AND METHODS}

\subsection{Description of the Study Area}

Various types of vegetation communities utilised by grazers are found in Lake Nakuru National Park, the most dominant being Cynodon nlemfuensis grassland [20]. Other important grasslands which grazers utilise include Chloris gayana, Sporobolus spicatus and Themeda triandra. Lake shore vegetation comprising a mixture of Cyperus laevigatus, Cynodon dactylon and Sporobolus spicatus is also utilised. We distinguished eight physiognomic vegetation types within the above vegetation communities. In this study, these physiognomic vegetation types are classified as habitat types. They include the Lake shore vegetation which is dominated by Cyperus laevigatus, Sporobolus spicatus and Cynodon dactylon; Short open grassland $\approx$ below $30 \mathrm{~cm}$ tall; Medium open grassland $\approx 30 \mathrm{~cm}$ to $1 \mathrm{~m}$ tall; Tall open grassland $\approx$ above $1 \mathrm{~m}$ tall; Swamp, flooded and riverine vegetation dominated by Cyperus laevigatus and Typha domingensis. Riverine vegetation is dominated by Acacia xanthophloea and A. albida; Open Tarchonanthus bush; Open Acacia woodland; and Woody vegetation comprising mainly of Solanum spp., Ocimum spp., Aspilia spp. and Rhus natalensis (Figure 1).

Rainfall pattern in the Park is bimodal, with a wet and a dry season occurring during the year. This study was conducted from the end of the long wet season of 1998 (late wet) with $171 \mathrm{~mm}$, to the dry season of 1999 with $37 \mathrm{~mm}$, and the early wet season of 1999 with $285 \mathrm{~mm}$ of rain.

\subsection{Botanical Composition of Diet}

Fresh dung samples belonging to African buffalo Syncerus caffer Sparrman, Burchell's zebra Equus burchelli, defassa waterbuck Kobus defassa Rüppell, warthog Pha- cocoerus aethiopicus Pallas, impala Aepyceros melampus Lichtenstein, and Grant's gazelle Gazella granti Brooke were collected during the study. Five pellets of fresh dung were collected from each individual. Dung samples collected in this manner from 15 individuals belonging to the same species were then composted into a single sample. Each composite sample was then air dried, ground and stored in an airtight polythene bag. Seasonal diet composition was determined by faecal analyses of the composite samples following a procedure described by [21].

\subsection{Habitat Use}

The area of the Park which the grazers utilise throughout the year was divided into five sites (Figure 1). In each site, a permanent road transect which traversed through the highest number of habitats was selected. Transect lengths were variable. Each transect was surveyed twice a month for one year from May 1998 to April 1999. An animal count was conducted during each survey. Morning counts started at $0600 \mathrm{~h}$ and ended at $0900 \mathrm{~h}$, while afternoon counts started at $1600 \mathrm{~h}$ and ended at $1830 \mathrm{~h}$ when it started getting dark. These time periods coincided with active foraging of the grazers in the Park. During each count, the habitat types where animals were found foraging and number of animals counted on either side of the road were recorded.

\subsection{Body Weight Classes}

African buffalo (631 kg), Burchell's zebra (235 kg), defassa waterbuck $(190 \mathrm{~kg})$, warthog $(73 \mathrm{~kg})$, impala $(52$ $\mathrm{kg})$, and Grant's gazelle $(50 \mathrm{~kg})$ were grouped into three body weight classes $>300 \mathrm{~kg}, 100-300 \mathrm{~kg}$ and $0-100$ $\mathrm{kg}$ based on their mean live body weights obtained from $[4,22,23]$.

\subsection{Data Analyses}

Overlap in diet composition and in habitat use were calculated using Pianka's index of resource overlap $\alpha=\sum \mathrm{P}_{\mathrm{ij}} \mathrm{P}_{\mathrm{ik}} / \sqrt{\left(\sum \mathrm{P}_{\mathrm{ij}}^{2} \times \sum \mathrm{P}_{\mathrm{ik}}^{2}\right)}$, where $\mathrm{P}_{\mathrm{ij}}$ and $\mathrm{P}_{\mathrm{ik}}=$ proportion that resource category $\mathrm{i}$ contributes to the resource use of grazer $\mathrm{j}$ and $\mathrm{k}$ [24]. Overlap in resource use was computed as the product of overlap in diet composition and that in habitat use. Niche breadth for diet composition and habitat use was calculated using [25] index $\mathrm{B}: \mathrm{B}=1 / \sum \mathrm{P}_{\mathrm{ij}}^{2}$, where $\mathrm{P}_{\mathrm{ij}}=$ proportional use by animal species $\mathrm{j}$ of resource category $\mathrm{i}$.

\section{RESULTS}

\subsection{Overlap in Diet Composition}

Seasonal overlap in diet composition between the 

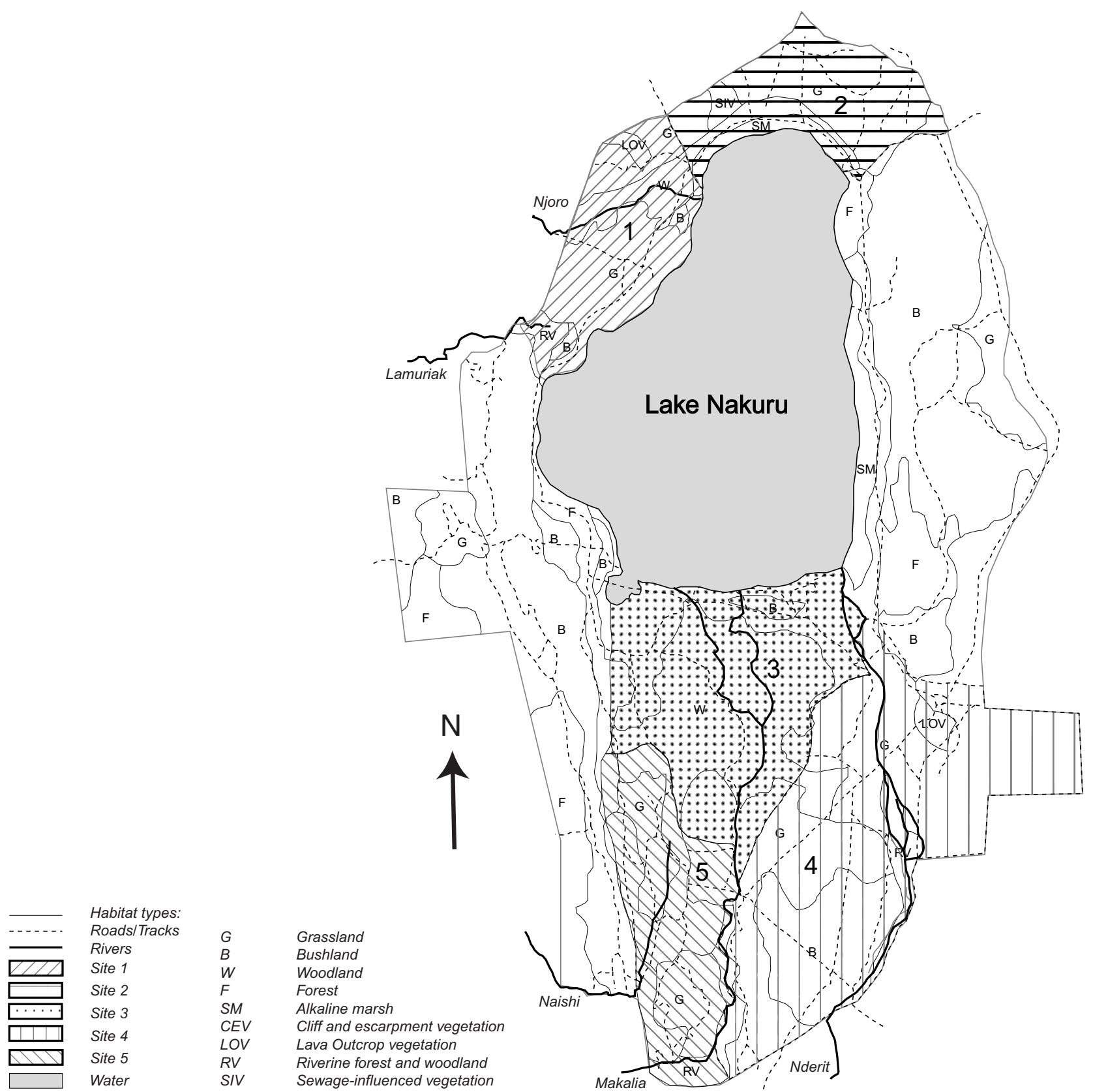

Figure 1. Map of Lake Nakuru National Park showing the location of study sites.

grazers was remarkable with the highest overlap, 0.94, observed during the early wet season between buffalozebra, and the lowest observed during the late wet season between buffalo-Grant's gazelle, 0.40. During the dry season, the highest overlap in diet composition, 0.87 was observed between zebra-warthog, while zebra-impala had the lowest overlap of 0.55 during this season. Grazers in similar body weight classes had their lowest overlap during the late wet season and highest during the early wet season: zebra-waterbuck, 0.56 ; warthog-impala, 0.6 ; warthog-Grant's gazelle, 0.7 ; and impala-Grant's gazelle, 0.64 (Table 1).

\subsection{Overlap in Habitat Use}

The highest overlap in habitat use, 0.99 was observed during the late wet season between Grant's gazelle-zebra, and the lowest, 0.79 between warthog-impala. During the dry season, waterbuck-zebra recorded the highest overlap, 0.97 and the lowest overlap, 0.79 was observed between warthog-impala, while in the early wet season, warthogzebra overlapped most, 0.96 , and warthog-impala overlapped the least, 0.48 in their habitat use. The lowest 
Table 1. Indices of overlap in diet composition between grazers in Lake Nakuru National Park.

\begin{tabular}{|c|c|c|c|c|c|c|}
\hline & & Buffalo & Zebra & Waterbuck & Warthog & Impala \\
\hline & Buffalo & & & & & \\
\hline & Zebra & 0.68 & & & & \\
\hline & Waterbuck & 0.65 & 0.56 & & & \\
\hline \multirow[t]{6}{*}{$\begin{array}{l}\text { Late wet } \\
\text { season }\end{array}$} & Warthog & 0.81 & 0.62 & 0.67 & & \\
\hline & Impala & 0.58 & 0.83 & 0.51 & 0.6 & \\
\hline & Grant's & 0.4 & 0.44 & 0.81 & 0.7 & 0.64 \\
\hline & Buffalo & & & & & \\
\hline & Zebra & 0.58 & & & & \\
\hline & Waterbuck & 0.76 & 0.75 & & & \\
\hline \multirow[t]{6}{*}{$\begin{array}{l}\text { Dry } \\
\text { season }\end{array}$} & Warthog & 0.62 & 0.87 & 0.79 & & \\
\hline & Impala & 0.81 & 0.55 & 0.68 & 0.63 & \\
\hline & Grant's & 0.55 & 0.75 & 0.74 & 0.8 & 0.78 \\
\hline & Buffalo & & & & & \\
\hline & Zebra & 0.94 & & & & \\
\hline & Waterbuck & 0.81 & 0.9 & & & \\
\hline \multirow[t]{3}{*}{$\begin{array}{c}\text { Early wet } \\
\text { season }\end{array}$} & Warthog & 0.57 & 0.66 & 0.84 & & \\
\hline & Impala & 0.75 & 0.82 & 0.85 & 0.93 & \\
\hline & Grant's & 0.82 & 0.81 & 0.87 & 0.68 & 0.73 \\
\hline
\end{tabular}

seasonal overlap in habitat use was observed between warthog-impala and this was consistent during the three seasons. Only warthog-impala showed a remarkable change in overlap from 0.79 in both the late wet and dry season to 0.48 in the early wet season, and warthogGrant's gazelle 0.91 , in late wet season to 0.97 in dry season to 0.78 in early wet season (Table 2).

\subsection{Overlap in Resource Use}

Zebra-waterbuck, 0.73; warthog-impala, 0.50; warthog-Grant's gazelle, 0.78 and impala-Grant's gazelle, 0.68 had a higher overlap in resource use in the dry season. Lowest overlaps in resource use were observed during the early wet season with warthog-impala, 0.44; warthog-Grant's gazelle, 0.53; zebra-waterbuck, 0.75 not changing much from the dry season. For warthog-impala, warthog-Grant's gazelle and impala-Grant's gazelle, overlap in resource use increased slightly during the succeeding late wet season. However, for zebra-waterbuck the overlap decreased. The highest overlap in resource use, 0.82 between grazers in different body weight classes i.e., zebra-warthog was recorded in the
Table 2. Indices of overlap in habitat use between grazers in Lake Nakuru National Park.

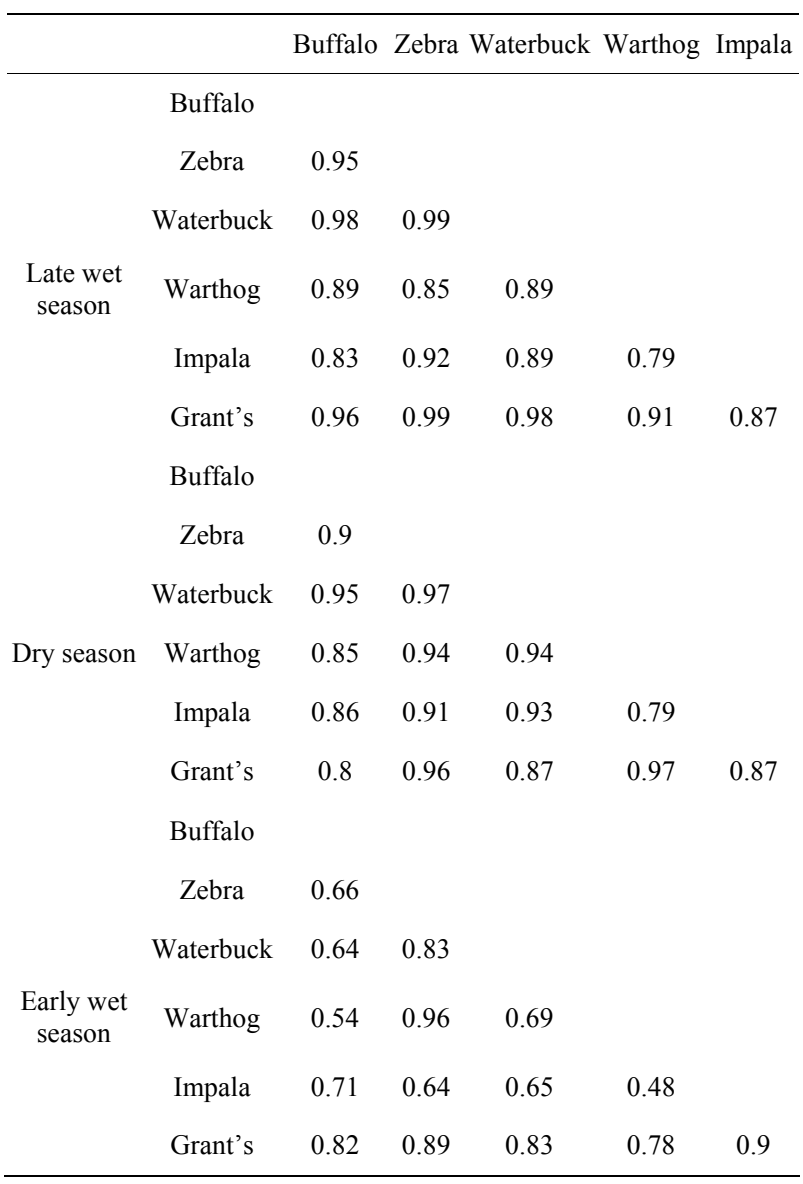

dry season (Table 3).

\subsection{Niche Breadth}

Niche breadth for diet composition was small $\left(\mathrm{B}_{\max }=\right.$ 12). The smallest niche breadth for buffalo, 5.34, zebra, 3.80 and waterbuck, 4.83 in diet composition were recorded during the dry season, while impala, 3.92 and Grant's gazelle, 4.9 had their smallest niche breadth for diet composition during the long wet season. Warthog had its smallest during the early wet season. Waterbuck had the highest shift in niche breadth from the dry to the early wet season, and also the largest niche breadth in diet composition, 8.30 compared to all other grazers. Niche breadth for habitat use was relatively small $\left(\mathrm{B}_{\max }=\right.$ 8) among the grazers. Like in diet composition, it was smallest in the long wet season, only warthog had its smallest niche breadth during the dry season (Table 4).

\section{DISCUSSION}

For species in similar body weight classes, the lowest overlap in diet composition was observed during the late wet season, probably because during this season which 
Table 3. Indices of overlap in resource use (diet composition and habitat use) between grazers in Lake Nakuru National Park.

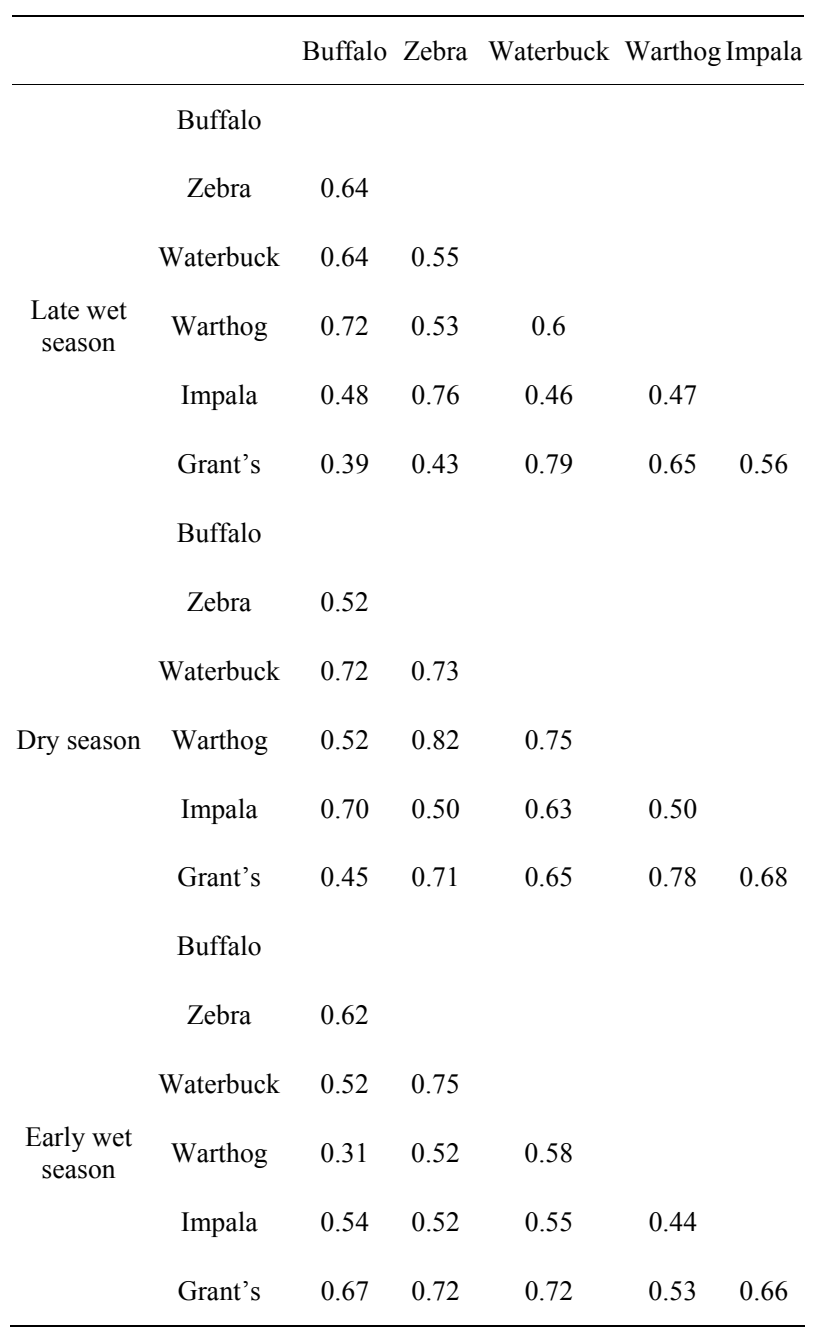

Table 4. Niche breadth for diet composition and habitat use by grazers. LW, late wet season; D, dry season; EW, early wet season.

\begin{tabular}{ccccccc}
\hline & \multicolumn{3}{c}{ Diet composition } & \multicolumn{3}{c}{ Habitat use } \\
\hline & LW & D & EW & LW & D & EW \\
\hline Buffalo & 5.45 & 5.34 & 5.69 & 2.05 & 2.46 & 3.46 \\
Zebra & 5.38 & 3.80 & 6.56 & 2.55 & 3.59 & 4.29 \\
Waterbuck & 6.77 & 4.83 & 8.30 & 2.28 & 2.72 & 2.77 \\
Warthog & 5.20 & 4.50 & 4.45 & 2.86 & 2.73 & 2.78 \\
Impala & 3.92 & 6.48 & 4.58 & 3.13 & 3.54 & 3.05 \\
Grant's gazelle & 4.90 & 6.09 & 7.18 & 2.34 & 3.99 & 4.05 \\
\hline
\end{tabular}

succeeded the early wet season, most grasses which were the dominant forage items for the grazers [26], and liberally available in the Park during the early wet growing season had now become fibrous and senescent making the grazers experience a lesser forage choice. In the process they might have differently specialized on fewer forage species thus exhibiting the lowest overlap in diet composition. The dry season of 1999 received rainfall, which was abnormal because traditionally it doesn't receive any, and because of this, green standing crop biomass was still available during this season. In fact from field observations, perennial grasses were observed sprouting and new herbs growing during this season. This explains the lack of lowest overlap during this season as initially predicted since the grazers did not necessarily have to lower their overlap in diet composition because there was still adequate forage available.

There was lack of a discernible seasonal variation in overlap in habitat use between grazers in similar body weight classes among the three seasons. In fact overlap indices were consistently high during the seasons. This lack of a clear trend in overlap in habitat use and the fact that the overlaps between grazers within the same body weight classes were consistently high suggest that no reasonable change in seasonal habitat use occurred in the Park among the grazers contrary to what [27] found out. The habitats during the time of this study were more compressed with a higher population density of large grazers than when [27] conducted their field work five years earlier.

Coexisting grazers especially those in similar body weight classes are expected to segregate more in their resource use during period of resource limitation, and that their niche breadth becomes smaller [15]. Our results did not comply with this prediction since resource segregation and smallest niche breadth were not observed during the dry season which is traditionally the resource limiting period. This is explained by the fact that seasonal differences in overlap in resource use were not outspoken, and also that possibilities for niche "contraction" in the dry season were limited leaving the grazers with little chance to move to a species-specific niche in order to have the lowest niche breadth in diet composition and habitat use. If we consider a resource use overlap of 0.54 to be the critical limit to similarity for coexisting species $[28,29]$, then our results indicate that overlap in resource use between grazers in similar body weight classes has exceeded this limit. This leaves no doubt that the grazers are competitively interacting with each other within the assemblage. The interactions are playing a critical role in the functioning and structuring of this assemblage, and should thus be considered central in the wildlife management of the Park.

\section{ACKNOWLEDGEMENTS}

The authors thank Kenya Wildlife Service for giving permission to conduct this study in Lake Nakuru National Park, and to the Netherlands Organisation for International Cooperation in Higher Education 
(NUFFIC) for funding the study.

\section{REFERENCES}

[1] Bell, R.H.V. (1971) A grazing ecosystem in the Serengeti. Scientific American, 225, 86-93.

http://dx.doi.org/10.1038/scientificamerican0771-86

[2] Field, C.R. (1972) The food habits of wild ungulates in Uganda by analyses of stomach contents. East African Wildlife Journal, 10, 17-42.

[3] Hofmann, R.R. (1973) The ruminant stomach. East African Literature Bureau, Nairobi.

[4] Prins, H.H.T. and Olff, H. (1998) Species richness of African grazer assemblages: Towards a functional explanation. In: Newbery, D.M., Prins, H.H.T. and Brown, N.D., Eds., Dynamics of Tropical Communities, Blackwell Science, Oxford, 449-490.

[5] Van Wieren, S.E. (1996) Digestive strategies in ruminants and non-ruminants. Ph.D. Thesis, Wageningen University, The Netherlands.

[6] Schuette, J.R., Leslie Jr., D.M., Lochmiller, R.L. and Jenks, J.A. (1998) Diets of hartebeest and roan antelope in Burkina Faso: Support of the long-faced hypothesis. Journal of Mammology, 79, 426-436. http://dx.doi.org/10.2307/1382973

[7] De Boer, W.F. and Prins, H.H.T. (1990) Large grazers that strive mightily but eat and drink as friends. Oecologia, 82, 264-274. http://dx.doi.org/10.1007/BF00323544

[8] Fritz, H., De Garine-Wichatitsky, M. and Letessier, G. (1996) Habitat use by sympatric wild and domestic grazers in an African savanna woodland: the influence of cattle spatial behaviour. Journal of Applied Ecology, 33, 589-598. http://dx.doi.org/10.2307/2404987

[9] Philipson, J. (1975) Rainfall, primary production and "carrying capacity" of Tsavo National Park, Kenya. East African Wildlife Journal, 13, 171-201.

[10] Sinclair, A.R.E. (1975) The resource limitation of tropic levels on tropical grassland ecosystems. Journal of Animal Ecology, 44, 497-520.

http://dx.doi.org/10.2307/3608

[11] Wrench, J.M., Meissner H.H. and Grant, C.C. (1997) Assessing diet quality of African ungulates from faecal analyses: The effect of forage quality, intake and grazer species. Koedoe, 40, 125-137. http://dx.doi.org/10.4102/koedoe.v40i1.268

[12] Voeten, M.M. (1999) Living with wildlife: Coexistence of wildlife and livestock in an East African savanna system. Tropical Resource Management Papers, No. 29, Wageningen University, Wageningen.

[13] Gordon, I.J. and Illius, A.W. (1989) Resource partitioning by ungulates on the Isle of Rhum. Oecologia, 79, 383389. http://dx.doi.org/10.1007/BF00384318

[14] Dekker, B., Van Rooyen, N., Bothma, J. and Du, P. (1996) Habitat partitioning by ungulates on a Game Ranch in the Mopani veld. South African Journal of Wildlife Research, 26, 117-122.

[15] Begon, M., Mortimer, M. and Thompson, D.J. (1996) Population ecology: A unified study of animals and plants.
Blackwell Science, Oxford. http://dx.doi.org/10.1002/9781444313765

[16] Mishra, C., Van Wieren, S.E., Pieter, K., Heitkönig, I.M.A. and Prins, H.H.T. (2004) Competition between domestic livestock and wild bharal Pseudois nayaur in the Indian trans-Himalaya. Journal of Animal Ecology, 73, 344-354.

[17] Prins, H.H.T., De Boer, W.F., Van Oeveren, H., Correia, A., Mafuca, J. and Olff, H. (2006) Coexistence and niche segregation of three small bovid species in southern Mozambique. African Journal of Ecology, 44,186-198. http://dx.doi.org/10.1111/j.1365-2028.2006.00619.x

[18] Azevedo, F.C.C., Lester, V., Gorsuch, W., Larivière, S., Wirsing, A.J. and Murray, D.L. (2006) Dietary breadth and overlap among five sympatric prairie carnivores. Journal of Zoology, 269, 127-135.

http://dx.doi.org/10.1111/j.1469-7998.2006.00075.x

[19] Ahrestani, F.S., Heitkonig, I.M.A. and Prins, H.H.T (2012) Diet and habitat-niche relationships within an assemblage of large herbivores in a seasonal tropical forest. Journal of Tropical Ecology, 28, 385-394. http://dx.doi.org/10.1017/S0266467412000302

[20] Mutangah, J.G. (1994) The vegetation of Lake Nakuru National Park, Kenya: A synopsis of the vegetation types with annotated species list. Journal of East African Natural History, 83, 71-96.

http://dx.doi.org/10.2982/0012-8317(1994)83[71:TVOL $\mathrm{NN}\rceil 2.0 . \mathrm{CO} ; 2$

[21] De Jong, C.B., Gill, R.M.E., Van Wieren, S.E. and Burlton, F.W.E. (1995) Diet selection by roe deer (Capreolus capreolus L.) in Kielder forest in relation to plant cover. Forest Ecology Management, 79, 91-97. http://dx.doi.org/10.1016/0378-1127(95)03622-9

[22] Haltenorth, T. and Diller, H. (1980) Mammals of Africa including Madagascar. Harper Collins, Hong Kong.

[23] Skinner, J.D. and Smithers, R.H.N. (1990) The mammals of Southern African subregion. 2nd Edition, University of Pretoria, Pretoria.

[24] Pianka, E.R. (1973) The structure of lizard communities. Annual Review of Ecology and Systematics, 4, 53-77. http://dx.doi.org/10.1146/annurev.es.04.110173.000413

[25] Levins, R. (1968) Evolution in changing environments. Princeton University Press, Princeton.

[26] Mwasi, S.M. (2002) Compressed nature: Coexisting grazers in a small reserve in Kenya. Ph.D. Thesis, Wageningen University, Wageningen.

[27] Mwangi, E.M. and Western, D. (1998) Habitat selection by large herbivores in Lake Nakuru National Park, Kenya. Biodiversity and Conservation, 7, 1-8. http://dx.doi.org/10.1023/A:1008891027230

[28] MacArthur, R.H. and Levins, R. (1967) The limiting similarity, convergence and divergence of coexisting species. American Naturalist, 101, 377-385. http://dx.doi.org/10.1086/282505

[29] Putman, R.J. (1996) Competition and resource partitioning in temperate ungulate assemblies. Chapman and Hall, London. http://dx.doi.org/10.1007/978-94-009-1517-6 